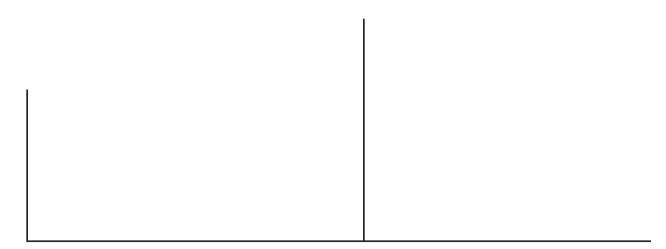

Rev. Latinoam. Psicopat. Fund., III, 4, 48-58

\title{
As relações entre psicose e periculosidade: contribuições clínicas da concepção psicanalítica da passagem ao ato
}

\author{
Maria Cristina Bechelany Dutra
}

\begin{abstract}
O presente artigo trata da questão da periculosidade na psicose à luz das formulações clínicas de Jacques Lacan sobre a passagem ao ato, presentes no seminário proferido sobre o tema da angústia, em 1962/1963. Com este aparato teórico, examinamos a passagem ao ato na psicose, levando em conta suas condições de realização, seus efeitos e suas relações com a periculosidade.
\end{abstract}

Palavras-chave: Psicose, periculosidade, passagem ao ato, psicanálise. 


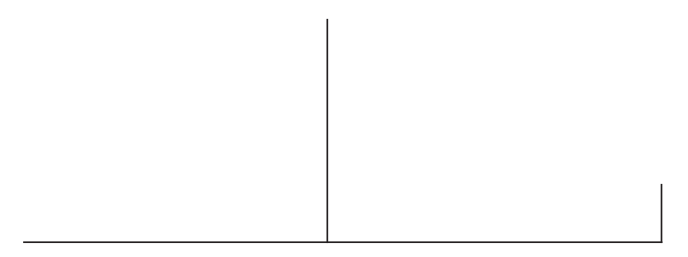

A importância do estudo da periculosidade na psicose revestese de relevância e atualidade por abarcar a interseção de dois campos de saberes distintos: o campo do direito penal e aquele da saúde mental, ambos apresentando, no momento atual, a particularidade de estarem sendo objeto de questionamentos e de reformas.

O conceito de periculosidade está logicamente ligado à noção de perigo, que se define como probabilidade de dano. $\mathrm{Na}$ periculosidade criminal, o acontecimento danoso que se julga provável é o crime. Esse juízo de probabilidade assenta-se no conhecimento de que o indivíduo reúne condições de desajustamento social de tal natureza e tamanho grau que possibilitam a prática de um ato punível. Portanto, a perigosidade criminal "é sempre uma fórmula individual integrada pela personalidade biológico-social do homem, em todos os seus aspectos" (Bruno, 1959: 189). Tal conceito baseia-se na probabilidade de que um indivíduo possa vir a cometer um crime e visa à possibilidade de sua prevenção.

Os indivíduos considerados inimputáveis, dos quais fazem parte os doentes mentais, são considerados como perigosos no Código Penal Brasileiro.

Se no campo do direito, a periculosidade refere-se à probabilidade da prática de um ato criminoso, no campo da clínica psiquiátrica e psicanalítica, ela refere-se à passagem ao ato. Por esta razão, por um lado, levando-se em conta a concepção psiquiátrica, pois não será sem o seu aval e sem a sua sustentação que o Direito Penal acolherá o conceito de periculosidade referindo-o aos doentes mentais, investigamos alguns quadros clínicos que, ao longo da história da psiquiatria, apresentavam em sua descrição o risco de ocorrência de passagens ao ato agressivas e delituosas. 


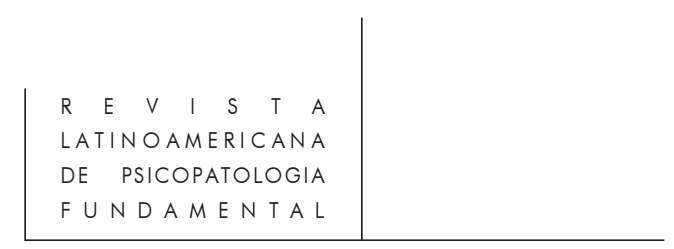

Por outro lado, abordamos a questão da periculosidade na psicose baseada nas contribuições da concepção psicanalítica da passagem ao ato, utilizando as formulações clínicas propostas por J. Lacan sobre este tema, durante o seminário proferido nos anos de 1962-1963 sobre a angústia.

No campo da psiquiatria, vários autores, em épocas diversas, abordaram a propensão dos doentes mentais, e particularmente dos psicóticos, à violência e ao crime. Os primeiros trabalhos relacionando a loucura ao crime e conseqüentemente à periculosidade aparecerão no início do século XIX com Esquirol, quase concomitante à própria fundação da clínica psiquiátrica, ao introduzir na nosologia psiquiátrica a classe das monomanias instintivas. Nestas, o sujeito pode ser conduzido a ações delituosas, criminais e até homicidas. Dessa forma, Esquirol faz entrar na patologia mental condutas criminais que até então só interessavam à justiça e às suas sanções.

Outros autores relacionaram a doença mental à periculosidade, como Morel e Magnan que sustentaram, cada um a seu modo, a existência de uma "hereditariedade" decisiva na etiologia da doença mental, marcada por uma degeneração progressiva do indivíduo, que se expressava fundamentalmente no âmbito do comportamento, sendo este considerado desviado e deficitário. As condutas criminais localizavam-se no bojo destes desvios e eram características dos indivíduos degenerados. Além disso, ao descrever o delírio crônico de evolução sistemática, pertencente ao grupo das psicoses, Magnan colocou em pauta o problema da periculosidade pré-delitual, ao ressaltar o risco de passagens ao ato criminosas quando o paciente encontrava-se na terceira fase da doença, a fase de perseguição, e ao indicar, nesta fase, medidas preventivas de segurança para a proteção do doente e da comunidade em que vivia, antes que qualquer ato delituoso tenha sido cometido.

No início do século XX, com a constituição da psiquiatria clássica e a introdução de novas entidades nosológicas que, se não permaneceram até os dias de hoje, com certeza tiveram influência marcante na construção da nosografia atual, novos quadros se relacionaram ao risco de passagens ao ato agressivas, como o delírio de reivindicação de Sérieux e Capgras, a erotomania de Clérambault, e a descrição do período médico-legal prodrômico da esquizofrenia, estabelecendo novas conexões com a noção de periculosidade na psicose.

$\mathrm{O}$ estudo dos diversos autores pesquisados aponta para o desconhecimento e o desinteresse com relação aos aspectos psicológicos do indivíduo. A idéia de uma motivação para estes atos não era nem mesmo interrogada, já que a inferência à causalidade orgânica tomava o doente e seus sintomas como inexoravelmente desprovidos de razão e sentido.

Guiraud promove uma ruptura com esta concepção deficitária da loucura na medida em que propõe uma teoria específica para lidar com o tema dos assassina- 


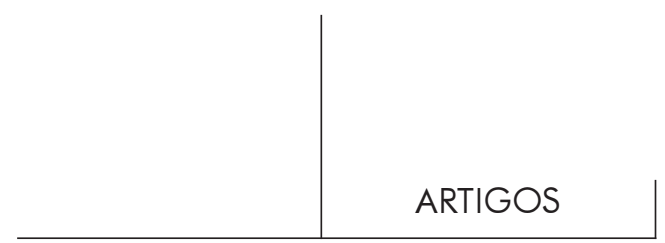

tos imotivados na psicose. Ele insiste no fato de que, apesar destes crimes ditos "imotivados" acontecerem sem a intervenção de uma impulsão ou mesmo de uma idéia delirante, eles devem ser pesquisados com relação à sua motivação, pois devese esperar também deles a existência de causas precisas. Entendendo que as questões inconscientes podem ser forças motivadoras destes atos violentos, Guiraud introduz o conceito de kakon, referindo-o ao mal-estar que invade o sujeito decorrente da doença. O kakon, projetado na sociedade e por um trabalho de simbolização, representado pelo mal social, por dedução lógica deveria ser suprimido. Por esta via, a tão inusitada reação violenta emergiria, com o objetivo de desembaraçar o sujeito do kakon que o invadia. Estes atos, pois, não constituíam atos sem causa, pelo contrário, representavam um último esforço do sujeito para se libertar da doença.

Dentro desta mesma lógica, e utilizando as concepções introduzidas por Guiraud, Lacan, em sua tese de doutorado em medicina, descreveu a paranóia de autopunição, analisando-a também à luz das contribuições de Freud, e enfocando os riscos inerentes a ela no que concernia às passagens ao ato. Ele adotou a concepção de Guiraud do mecanismo liberador do kakon nos homicídios imotivados, aproximando-a da passagem ao ato de Aimée.

A periculosidade na psicose, abordada segundo a perspectiva do direito e da psiquiatria, é pois um conceito que abarca uma concepção da loucura como déficit e como ausência de individualidade e subjetividade. A psicanálise, por sua vez, como vimos com Guiraud e Lacan, consegue romper com o determinismo do déficit, pois ao considerar a noção de motivação, concomitantemente insinua a idéia da existência de um sujeito que, embora louco, não está excluído de uma certa responsabilidade e saber com relação a seus atos.

Para abordarmos a psicose segundo o referencial teórico da psicanálise lacaniana, fez-se necessário investigarmos seus fundamentos. Inicialmente fundada sobre a idéia de uma Bejahung que falta, em seguida relaciona-se à falta de um significante primordial, o significante do Nome-do-Pai, e ao complexo de Édipo, e posteriormente à não extração do objeto a. Se há foraclusão do significante do Nome-do-Pai na psicose, não há a perda fundadora e estruturante da castração simbólica. O sofrimento do psicótico está ligado a uma operação de separação que não aconteceu. Dito de outra maneira, não houve extração do objeto a do campo do Outro. E esta extração, que correlaciona-se com a castração, é o que limita e contém o gozo puro e desmedido presente no corpo do sujeito denominado gozo do Outro, inaugurando um outro tipo de gozo, o gozo fálico, condição de possibilidade do exercício de uma sexualidade normal.

Na psicose, por falta da extração do objeto a, há um defeito na significantização do gozo, que permanece como um real em excesso. O psicótico encontra-se, assim, identificado à posição de objeto de gozo para o Outro, ao qual ele irreme- 


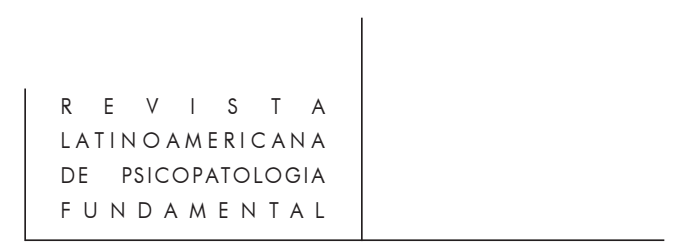

diavelmente se submete. Ele se oferece como objeto no lugar onde falta a falta (Alvarenga, mimeo.); objeto que terá o estatuto de dejeto, de puro real, desvinculado da castração e do desejo do Outro.

O psicótico vive na exigência de uma demanda contínua por parte de um Outro absoluto e gozador, ao qual ele tem de se oferecer como objeto, testemunhando uma exigência de sacrifício. Ele sacrifica-se pelo Outro para fazê-lo gozar e paga, como nos mostra Schreber, com seu próprio corpo o preço deste gozo.

A concepção psicanalítica da passagem ao ato desenvolvida por Lacan, no seminário sobre a angústia, encontra-se desvinculada de quaisquer categorias diagnósticas, na medida em que concebe a dimensão do agir em duas grandes vertentes, aquela do significante (ou do Outro), representada pelo acting out, e aquela do objeto, representada pela passagem ao ato, em relação às quais ressalta as particularidades da posição do sujeito. Neurose, psicose e perversão podem hospedar ambas as vertentes e a passagem ao ato deixa de ser exclusiva daquelas "estruturas de personalidade" destacadas pela psiquiatria, abandonando as características que até então a resumiam, para se localizar como um fenômeno clínico que respeita uma determinada lógica, fundada na relação do sujeito com o objeto.

Para Lacan (1962: 84), o ato é o que pode fundar para o sujeito uma certeza. Assim concebido, o ato representa o avesso do pensamento, cujo paradigma é a incerteza, o equívoco e a dúvida. Nesta perspectiva, a passagem ao ato é o movimento que consiste em separar a vida de sua tradução, de sua transposição no Outro. Ela representa este momento em que nenhum interlocutor e nenhuma mediação é possível e, contrariamente ao acting out que vem justamente no lugar de um dizer, ela é um "eu não quero dizer", promovendo assim uma separação radical com o Outro. Na passagem ao ato, um "não" profundo do sujeito é dirigido ao Outro. Concordando com Miller (1993) e com Sauvagnat (1988), podemos afirmar que a passagem ao ato é indiferente a seu futuro e tem sempre um aspecto resolutivo. O sujeito coloca verdadeiramente em jogo o seu ser, sem ter a noção da intensidade dramática de seu ato e pelo fato de não se inscrever no campo do Outro, ela não pode ser interpretada. Embora não seja um ato sem causa, esta causa é impossível de dizer, porque conjuga-se justamente com este objeto inassimilável pelo significante, que situa-se no Outro em exterioridade e que concerne ao gozo, a saber, o objeto a.

No desenvolvimento de sua teoria, Lacan ressalta: o que é "essencial em todo relacionamento súbito do sujeito com o que ele é como objeto a" é o "deixar-se cair", o lançar-se para fora da cena, ou segundo Freud (1920), o niederkommen (Lacan, 1963:118), correlatos essenciais da passagem ao ato.

A cena de que se trata aí é a cena da fantasia, concebida no seu aspecto estrutural de articulação do sujeito com o objeto, sendo, segundo Lacan, este quadro que se coloca 


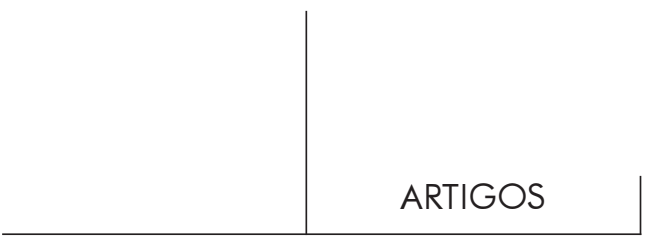

... no enquadramento da janela, técnica absurda sem dúvida, se se trata de ver melhor o que está no quadro, mas [...] não é disto que se trata, é, apesar do charme daquilo que está pintado na tela, de não ver o que se vê pela janela (Lacan, 1962: 81).

O que não se pode ver pela janela, e que é dissimulado pela tela da fantasia, é o objeto a, já que seu encontro com o sujeito provoca a angústia, sua única tradução subjetiva. A fantasia que preserva o sujeito deste encontro, quando vacila, precipita-o na angústia e no ato.

A passagem ao ato representa, pois, a reação de um sujeito caracterizada por uma profunda radicalidade, quando ele é confrontado ao que é como objeto a, ao qual ele se identifica e se reduz e que tem aqui essa conotação característica ligada à função de resto. E eis o que define a passagem ao ato: a saída da cena. É sempre esse caráter de evasão que nos permite reconhecê-la.

Duas condições são essenciais para a realização de uma passagem ao ato: por um lado, a vivência do que Lacan vai chamar de embaraço; e, por outro, a emoção.

O termo emoção etimologicamente refere-se a moção, movimento. Segundo Ferreira (1986), trata-se de um abalo moral, de uma reação intensa e breve do organismo a um lance inesperado, acompanhada de um estado afetivo de conotação penosa e desagradável.

O termo embaraço é por definição perturbação, impedimento, barreira, obstáculo (ibid.). É obstáculo à passagem, à ação, uma dificuldade que detém e perturba uma realização, uma vivência que se opõe à idéia de movimento. Estar embaraçado faz referência à barra colocada sobre o sujeito. O sujeito embaraçado, por estar sobrecarregado, acha-se em posição difícil e incômoda pela impossibilidade de movimento.

A barra posta sobre o sujeito refere-se à castração. Na passagem ao ato temos um sujeito que "se barre", ou seja, que foge diante do que se apresenta como angústia da castração. A identificação do sujeito com o objeto a, em sua função de dejeto, correlaciona-se pois à castração.

No momento da passagem ao ato, o sujeito encontra-se então numa encruzilhada, afetado por um supremo embaraço e comovido por uma intensa emoção.

Lacan trabalha, neste seminário, a passagem ao ato a partir da lógica do fantasma. Deste ponto de vista, não poderíamos incluir a psicose nesta formulação, pois sabemos que a fantasia, que é antes de tudo essa janela constituída pela extração do objeto a do campo da realidade, não aparece na psicose da mesma forma que na neurose. Julgamos portanto que pensar a passagem ao ato na psicose supõe ir além dessa elaboração presente no seminário da angústia. Parece-nos que o caminho que nos conduz à especificidade da passagem ao ato nesse âmbito é aquele que aparece precocemente no percurso de Lacan, a saber, a teoria do kakon. Tal- 


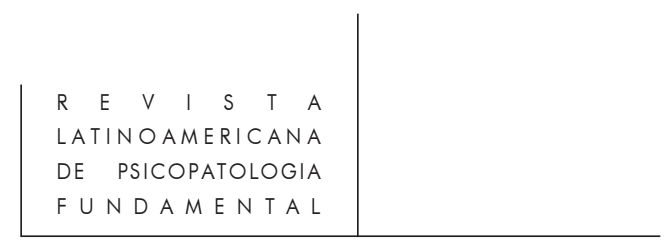

vez possamos dizer, como propõe Tendlarz (1995), que Lacan tenha-se utilizado deste termo exatamente para nomear o que ainda se encontrava fora de sua teorização e que constituiria um conceito essencial para tratar o ser do sujeito, ou seja, o gozo.

A passagem ao ato na psicose pode ser vista como essa tentativa de realizar a castração simbólica, à qual ele não teve acesso, pela via do real. Trata-se de obter a extração desse objeto, desse ponto de gozo que invade e submete, e ao mesmo tempo, a separação radical do Outro. Extrair esse objeto, que é ele mesmo, do campo do Outro, representa para o psicótico a possibilidade de libertação do Outro, conjugado com uma certeza que só poderia ser arrancada do próprio ato em si.

Dentro desta perspectiva, se o fundamento da análise do kakon de Guiraud era, como vimos, a projeção para o exterior do mal-estar que então surgia no interior do sujeito, em virtude da doença, podemos afirmar que a passagem ao ato do psicótico nada tem de uma projeção, na medida em que o objeto a, objeto a ser golpeado, embora se encontre em condição de exterioridade, representa nada menos que o próprio ser do sujeito ${ }^{2}$. A passagem ao ato na psicose não apresenta, pois, o caráter de uma projeção e sua significação repousa, muito antes, na idéia de um ato auto, do que na de um ato dirigido contra terceiros.

Diante do que foi exposto, pensamos a passagem ao ato na psicose não mais como um ato de características meramente impulsivas e sem sentido, mas inserida em uma lógica que orienta-se pela posição que o sujeito ocupa diante do Outro. Levando em conta a presença desta lógica, poderíamos indagar quais seriam as situações em que um risco de passagem ao ato deve ser considerado e nas quais uma presunção de periculosidade pode ser adequada.

O encontro com o Outro gozador será uma condição essencial para o desencadeamento de uma passagem ao ato na psicose. Segundo Maleval (1991), tanto a passagem ao ato, quanto o trabalho de mobilização significante são saídas vislumbradas pelo psicótico para se defender da angústia suscitada pelo encontro com o Outro gozador. A passagem ao ato ocorreria quando o sujeito não consegue operar eficazmente uma mobilização delirante do significante. Com a falência do recurso simbólico, não restaria ao psicótico outra possibilidade que não fosse lançar mão deste outro meio: o sacrifício de um objeto real.

Quando a confrontação com o gozo do Outro que desestabiliza o sujeito conjuga-se com um grande empobrecimento da linguagem, caracterizado por fenômenos de errância, de mutismo, de bizarria, de afastamento social etc., e com fenômenos

2. Miller, em 1988, propõe o kakon como um dos nomes do objeto como êxtimo, significando que o ser golpeado no exterior é o ser mais íntimo do sujeito. 


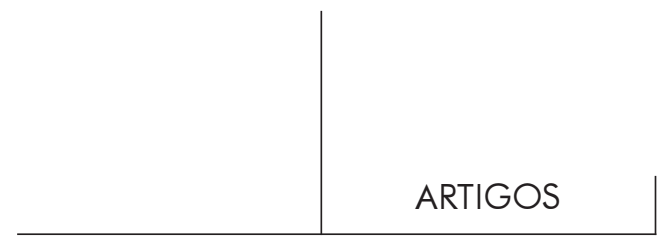

de transitivismo e mimetismo, próprios ao registro do imaginário, prevalentes na psicose e cujas marcas são a rivalidade e a agressividade, o risco de passagens ao ato deve ser vislumbrado. A passagem ao ato representaria, assim, uma tentativa de cura realizada pelo sujeito que, diante de um encontro dessa ordem e não estando em condições de mobilizar um significante para temperar a perplexidade angustiante que o assalta, lança mão do ato como uma saída possível.

A presença destes fenômenos, portanto, quando perceptíveis num sujeito psicótico, permitem-nos considerar a probabilidade de uma passagem ao ato e, impondo-se os riscos, avaliarmos a necessidade e a emergência das diversas intervenções possíveis.

A passagem ao ato tenderia a produzir o que Lacan chamou, em 1932, de alívio afetivo. Apesar disso, a passagem ao ato na psicose não produz, com relação ao quadro clínico e à responsabilização pelo ato, efeitos uniformes em todos os sujeitos. Maleval (1991) acredita que uma reação depressiva e uma preocupação em reparar seu ato seriam indispensáveis para que o sujeito consiga integrar psiquicamente sua realidade e elaborar uma "culpabilidade". Porém, não podemos afirmar que este caminho encontra-se traçado a priori. Cada sujeito pode percorrêlo à sua maneira. É o que nos mostra Althusser, que por ter sido considerado inimputável e não ter tido a oportunidade de responder na justiça pelo seu crime, escreve um livro, que supõe ser uma resposta.

De toda forma, Lacan ressalta que não se deve privar o doente de subjetivar seu crime, pois os efeitos da despossessão do sujeito de seu ato têm incidências nefastas sobre sua evolução clínica. Nesta perspectiva, deparamo-nos com outra questão, que é a forma como o Direito Penal encontrou para lidar com os doentes mentais que tenham cometido um crime, ou seja, por meio da inimputabilidade. Não nos caberia aqui examinar a pertinência ou não deste conceito, mas não podemos desconhecer que a justiça, neste âmbito, não faz mais que ratificar a posição de objeto que o sujeito psicótico ocupa diante do Outro gozador, destituindo-o de toda subjetividade $^{3}$.

Como afirmam Miller (1988), Sauvagnat (1990) e Izcovich (1991), é no sentido de uma certa aceitação e consentimento daquilo que chega ao sujeito psicótico, vindo do Outro, que a prevenção de uma passagem ao ato torna-se possível. É o que Lacan chama de "compromisso razoável" (Lacan, 1958: 573). Esse compromisso equivale a um certo "sim” àquilo que o Outro deseja do sujeito com relação ao gozo, sem significar porém uma desresponsabilização por parte do sujeito.

3. Sobre as conseqüências clínicas da inimputabilidade sobre o sujeito psicótico, ver dissertação de mestrado de Cheib (1998), sob orientação do prof. dr. Jésus Santiago. 


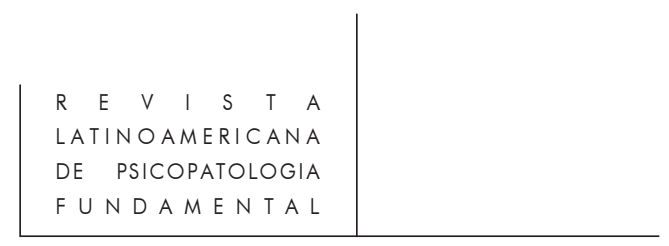

A passagem ao ato na psicose representaria uma tentativa de cura, na qual estaria em jogo a possibilidade de extração do objeto a, ou do gozo, do campo do Outro, para se chegar, consequientemente, a uma desesperada desconexão com o Outro. Assim sendo, talvez possamos afirmar que o sujeito psicótico, mais comumente que o neurótico, acaba por lançar mão dessa saída, que é a passagem ao ato, contribuindo para uma maior aproximação entre psicose e periculosidade. A passagem ao ato, ao inserir-se numa lógica própria, deixa de ser um ato impulsivo e sem sentido e passa a relacionar-se a determinadas condições que devem ser reconhecidas para que possamos, como clínicos, intervir quando isso for necessário e possível.

Com o movimento da reforma psiquiátrica e a inauguração de um novo lugar social para a loucura, que ultrapassa a fronteira da desinstitucionalização para envolver a sociedade de maneira geral e seus fundamentos, exemplarmente ilustrado neste momento em que se discute a reforma do Código Penal, na qual o conceito de periculosidade torna-se alvo de críticas pela evidente discriminação que representa, percebemos o quanto o fenômeno clínico da passagem ao ato reveste-se de importância e de atualidade. Este trabalho não pretendeu, evidentemente, esgotar tema tão complexo e ainda tão enigmático, porém esperamos poder, de alguma forma, contribuir nesta árdua tarefa do clínico de tentar reconhecer, lidar, evitar as passagens ao ato, em suas diversas modalidades.

\section{Referências Bibliográficas}

Althusser, L. O futuro dura muito tempo. São Paulo: Companhia das Letras, 1992. $316 \mathrm{p}$.

Alvarenga, M.E. Holderlin: o objeto na psicose. Belo Horizonte. (Mimeo.).

Bercherie, P. Os fundamentos da clínica. Rio de Janeiro: Jorge Zahar, 1989. $332 \mathrm{p}$.

Bruno, A. Direito penal. Parte geral. 2a ed. Rio de Janeiro: Forense, 1959. t. I e II.

Cottet, S. O paradoxo do gozo. Transcrição. Salvador. no 5, p. 5-53, jun 1989.

Delgado, P.G. As razões da tutela. Rio de Janeiro: Te Corá, 1992. 284p.

Ferreira, A.B.H. Novo Dicionário Aurélio da Língua Portuguesa. 2a ed., rev. e ampl. Rio de Janeiro: Nova Fronteira, 1986.

Freud, S. (1920). A psicogênese de um caso de homossexualismo numa mulher. ESB. Rio de Janeiro: Imago, 1976.

Guiraud, P.; Cailleux, B. Le meurtre immotivé, réaction libératrice de la maladie, chez les hébéphrénique. Annales médico-psychologiques. t. 1 e 2, 12ª série, 1928.

Guiraud, P. Les meurtres immotivés. L'évolution psychiatrique. ํㅡㄹ 2, 2a série, mar, 1931. 


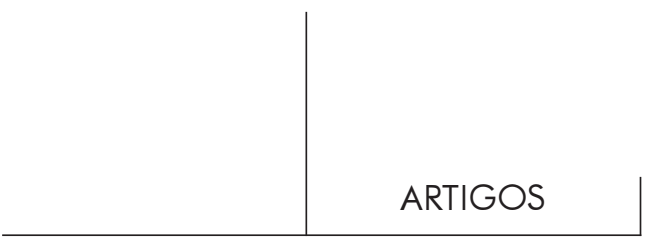

Izcovich, L. Incidences du transfert sur le passage a l'acte. Quarto oㅡㄴ 44/45, oct., 1991.

LACAN, J. (1932). Da psicose paranóica em suas relações com a personalidade. Rio de Janeiro: Forense-Universitária, 1987. 404p. (1956). O seminário. Livro 3. As psicoses. $2^{\mathrm{a}}$ ed. corrigida. Rio de Janeiro: Jorge Zahar, 1988.

(1958). O seminário. Livro 5. As formações do inconsciente. Rio de Janeiro: Jorge Zahar, 1999.

(1963). O seminário. Livro 10. A angústia. Publicação não comercial exclusiva para os membros do Centro de Estudos Freudianos do Recife, 1997.

Maleval, J.C. Logique du meurtre immotivé. Psychose naissante, psychose unique? Ouvrage collectif sous la direction du Dr. H. Grivois. Paris: Masson, 1991.

Miller, J.A. Cause e consentement. Curso no Departamento de psicanálise da Universidade de Paris VIII, inédito, lição de 20 de abril de 1988.

Jacques Lacan: observaciones sobre su concepto de pasaje al acto. In Infortunios del acto analitico. Coleccíon Algoritmo. Buenos Aires: Atuel, 1993.

SAUvaGnat, F. Le clinicien saisi par le passage à l'acte: quelques points d'histoire. Actualités Psychiatriques, no 1, jan., 1988.

La question des "passages a l'acte" en psychanalyse. Les monomanies instinctives. Sous la direction de H. Grivois. Paris: Masson, 1990.

Tendlarz, S. Guiraud: la immotivación del homicidio en la psicosis. Etiem/ “Caracterologia”. Buenos Aires. no 1, p. 79-86, 1995.

\section{Resumos}

El presente artículo trata de la cuestíon de la periculosidad en la psicosis basadas en las formulaciones clínicas de Jacques Lacan sobre el "pasaje al acto", presentes en el Seminario proferido sobre el tema de la angustia, en 1962/63. Com este aparato teórico, examinamos el "pasaje al acto" en la psicosis considerando sobretodo sus conditiones de realisación, sus efectos y sus relaciones com la periculosidad.

Palabras llave: Psicosis, periculosidad, pasaje al acto, psicoanalisis

Cet article aborde la question de la dangerosité dans la psychose à partir des formulations cliniques de Jacques Lacan sur le passage à l'acte, apparues dans le seminaire sur l'angoisse, de 1962/63. Avec cet apparat théorique, on examine le passage à l'acte dans la psychose, ses conditions de realizations, ses effets e ses relations avec la dangerosité.

Mots clés: Psychose, dangerosité, passage à l'acte, psychoanalyse 


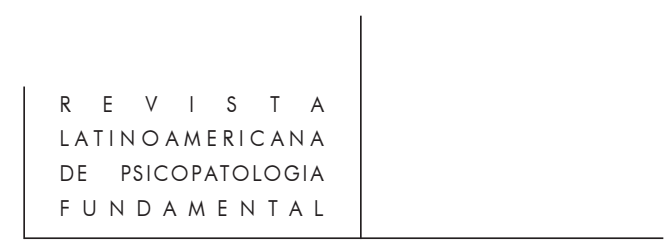

The present article treats the question of dangerousity in psychosis based on the clinical formulations of Jacques Lacan over "passage à l'acte", present at the seminary of anguish (1962/63). With this theoretical apparatus, we will examine the "passage à l'acte" in psychosis, considering its conditions of happening, its effects and its relations with the dangerousity.

Key words: Psychosis, dangerousity, passage à l'acte, psychoanalysis

Versão inicial recebida em julho de 2000.

Versão revisada recebida em novembro de 2000. 